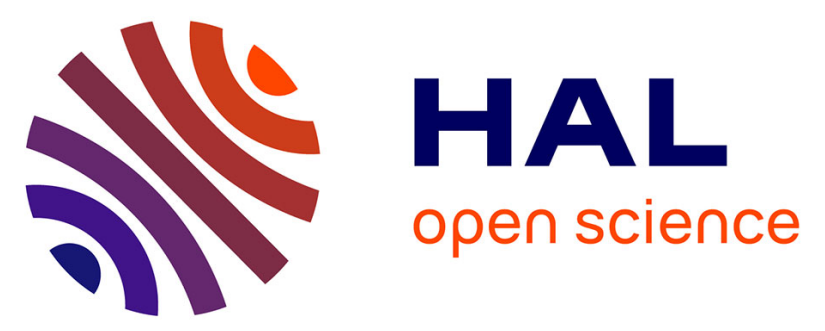

\title{
Methodological Considerations to Investigate Dosage Parameters of Intensive Upper Limb Rehabilitation in Children with Unilateral Spastic Cerebral Palsy: A Scoping Review of RCTs
}

Lucas Ravault, Nelly Darbois, Nicolas Pinsault

\section{To cite this version:}

Lucas Ravault, Nelly Darbois, Nicolas Pinsault. Methodological Considerations to Investigate Dosage Parameters of Intensive Upper Limb Rehabilitation in Children with Unilateral Spastic Cerebral Palsy: A Scoping Review of RCTs. Developmental Neurorehabilitation, 2020, 23 (5), pp.309-320. 10.1080/17518423.2019.1687599 . hal-02889431

\section{HAL Id: hal-02889431 \\ https://hal.science/hal-02889431}

Submitted on 21 Aug 2020

HAL is a multi-disciplinary open access archive for the deposit and dissemination of scientific research documents, whether they are published or not. The documents may come from teaching and research institutions in France or abroad, or from public or private research centers.
L'archive ouverte pluridisciplinaire HAL, est destinée au dépôt et à la diffusion de documents scientifiques de niveau recherche, publiés ou non, émanant des établissements d'enseignement et de recherche français ou étrangers, des laboratoires publics ou privés. 


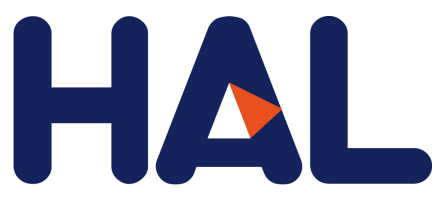

archives-ouvertes

\section{Methodological Considerations to Investigate Dosage Parameters of Intensive Upper Limb Rehabilitation in Children with Unilateral Spastic Cerebral Palsy: A Scoping Review of RCTs}

Lucas Ravault, Nelly Darbois, Nicolas Pinsault

\section{To cite this version:}

Lucas Ravault, Nelly Darbois, Nicolas Pinsault. Methodological Considerations to Investigate Dosage Parameters of Intensive Upper Limb Rehabilitation in Children with Unilateral Spastic Cerebral Palsy: A Scoping Review of RCTs. Developmental Neurorehabilitation, Informa Healthcare, 2020, 23 (5), pp.309-320. 10.1080/17518423.2019.1687599 . hal-02889431

\section{HAL Id: hal-02889431 \\ https://hal.archives-ouvertes.fr/hal-02889431}

Submitted on 21 Aug 2020

HAL is a multi-disciplinary open access archive for the deposit and dissemination of scientific research documents, whether they are published or not. The documents may come from teaching and research institutions in France or abroad, or from public or private research centers.
L'archive ouverte pluridisciplinaire HAL, est destinée au dépôt et à la diffusion de documents scientifiques de niveau recherche, publiés ou non, émanant des établissements d'enseignement et de recherche français ou étrangers, des laboratoires publics ou privés. 


\title{
Methodological Considerations to Investigate Dosage Parameters of Intensive Upper Limb Rehabilitation in Children with Unilateral Spastic Cerebral Palsy: A Scoping Review of RCTs
}

\author{
Lucas Ravault, Nelly Darbois, and Nicolas Pinsault

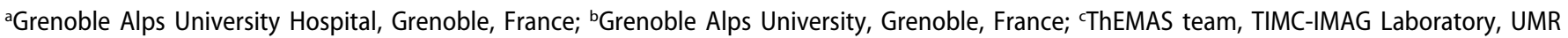 \\ CNRS-UGA 5525, Grenoble, France
}

\begin{abstract}
Purposes: To identify and synthesize RCTs on the isolated effect of dosage parameters of upper limb Intensive Motor Rehabilitation Treatments (IMRT) of children with Unilateral Spastic Cerebral Palsy (USCP); to identify the most frequent methodological weaknesses.

Methods: Searches were conducted until September 2018 in gray and published literature databases and supplemented by exploring the identified studies' references. Inclusion criteria applied: RCT; children aged 1.5 to 19 years with USCP; upper limb IMRT differing only from $\geq 1 / 4$ dosage parameters between groups. Literature analyses conducted: qualitative and descriptive.

Results: We identified 461 studies. Seventeen were included: three presented a rehabilitation dosage distinction between groups in Frequency-Time, four in Intensity-Progressivity, three in IntensityRestraint, two in Intensity-Environment and five presented $\geq 3$ distinctions above.

Conclusions: Inconsistencies were noted between USCP lifelong issues, and the short follow-ups and lack of participation assessments. Confounding factors and misstatements in Intent To Treat (ITT) analyses were identified. A meta-analysis was considered irrelevant.
\end{abstract}

Abbreviations: USCP, CP: Unilateral Spastic Cerebral Palsy, Cerebral Palsy; RCT: Randomized Controlled Trial; IMRT: Intensive Motor Rehabilitation Treatment
ARTICLE HISTORY

Received July 17, 2019

Revised October 24, 2019

Accepted October 29, 2019

\section{KEYWORDS}

Cerebral palsy; intensive motor rehabilitation; dosage parameter; critical thinking; pediatrics

\section{Introduction}

Unilateral Spastic Cerebral Palsy (USCP) affects nearly 34\% of the children presenting Cerebral Palsy $(\mathrm{CP})$; this proportion has increased in Europe since the end of the $2 \mathrm{O}^{\text {th }}$ century. ${ }^{1}$ Between 1.6/1000 and 2.8/1000 births lead to CP depending on the region of the world. This proportion increased with low gestation age, low birth weight, twin or multiple pregnancy, and ethnic variations. ${ }^{1,2}$

USCP is clinically manifested by spastic hemiplegia with retractions, impaired motor command and control, and varying degrees of sensory, cognitive and epileptic disorders. ${ }^{2-5}$ These disorders result in a "developmental disregard" ${ }^{\text {of }}$ the hemiplegic upper-limb: "a certain portion of the motor deficit $[\ldots]$ is the result not of the damage per se but of a learning phenomenon stemming from the damage, but whose core is the learned suppression of movement". ${ }^{7}$ These function deficits secondly have a negative impact on the child's level of activity and level of participation. ${ }^{2,8}$ On the other hand, ambulation capacities are almost systematically preserved. ${ }^{9}$

In order to potentiate the improvement of motor functions and activities in the short and long term in children with USCP, many systematic reviews recommend motor rehabilitation: (1) early ${ }^{10},(2)$ adapted to the subtype of $\mathrm{CP}^{10},(3)$ and intensively ${ }^{11}$; that is often the case for bimanual training, constraint-induced movement therapy, context-focused therapy, goal-directed/functional training, home-programs integration. ${ }^{11-15}$

Several systematic and non-systematic reviews focused on the management of USCP, agree on the added value of these intensive motor rehabilitation treatments (IMRT) compared to those considered "conventional" and/or "non-intensive" and/or not fully taking into account the principles of motor learning. ${ }^{11,13-17}$ However, these scientific works are largely based on studies whose treatment types differ between the intervention and control groups (e.g. Sakzewski's metaanalysis ${ }^{11}$ includes studies comparing "modified ConstraintInduced Movement Therapy" (m-CIMT) to "Hand-Arm Bimanual Intensive Therapy" (HABIT) ${ }^{18}$ or "Standard Occupational Therapy" ${ }^{19}$ or other various treatments. ${ }^{20}$

The treatment type can be considered as a cluster of several distinct dosage parameters; comparing different types of treatments is like comparing two combinations of dosage parameters and their interactions. This represents many confounding factors that prevent the analysis of the specific effect of each dosage parameter of these IMRT on motor function.

Other authors have also described "intensive therapies" targeting the trunk and/or upper and/or lower limbs of

CONTACT Lucas Ravault lucasravault73@orange.fr 35 avenue des follaz, Chambéry, Savoie73000, France

Color versions of one or more of the figures in the article can be found online at www.tandfonline.com/ipdr.

(-) Supplemental data for this article can be accessed publisher's website. 
children without specifying the subtype of CP concerned. They have not been able to conclude on the determinants of their effectiveness: due to a lack of studies and inclusion criteria that are probably too restrictive. ${ }^{21,22}$

A recent systematic review of the peer-reviewed literature, based on a standardized dosage terminology ${ }^{23}$ includes only studies comparing groups receiving the same type of treatment and differing by at least one dosage parameter. ${ }^{24}$ They suggest, "that higher amounts of therapy time may have a slightly greater benefit than low amounts of therapy for improving motor function" without reaching the clinically significant threshold. The lack of studies on the "frequency" of treatments and the absence of a study on "intensity" prevent the authors from concluding on these subjects. Again, the non-specification of CP subtypes in the inclusion criteria contributes to many confounding factors (e.g. various associated impairments, clinical expressions, inter-study treatments, and child's or family's functional expectations).

There is therefore still a blurred area today as to the relative influence of each dosage parameter on these short- and long-term functional and participation benefits in children with $\mathrm{CP} .^{16,24,25}$ Nor is there a synthesis of the methodological limitations of RCTs that would specifically challenge the dosage parameters in this area.

The purposes of this scoping review were: (1) to identify and synthesize RCTs that allowed to question individually the dosage parameters of IMRT of the upper limb of children with USCP, (2) to identify the most frequent methodological limitations of the RCTs on the subject and their report in order to improve the quality of future research, and (3) to discuss the relevance of conducting a systematic review or meta-analysis on the subject.

\section{Method}

A scoping review of RCTs was conducted by systematically exploring the existing randomized controlled literature on the following topic: the effects of the dosage parameters of IMRT of the upper limbs on functional and participation skills of children with Unilateral Spastic Cerebral Palsy (USCP). The method was based on Cochrane's guidelines (http://handbook-5-1.cochrane. org/; https://epoc.cochrane.org/resources/epoc-resourcesreview-authors). The protocol was registered on PROSPERO, CRD42018104517 (http://www.crd.york.ac.uk/PROSPERO/dis play_record.php?ID=CRD42018104517).

From the comparison of several reviews and recommendations standardizing the dosage terminology ${ }^{23,26-28}$, we built a critical terminology framework for the dosage parameters as follows:

- Frequency-Time: "How often during a fixed period the regimen is administered" and "the total amount of time that an intervention period occupies". ${ }^{26}$

- Intensity: The "amount of physical or mental work put forth by the client during a particular [...] activity during a defined period of time" ${ }^{26}$ [according to]:

$\circ$ the progressivity of tasks (e.g. shaping, progressive difficulty, goal-directed, recovery sessions).

o the restraint (e.g. sling/glove/cast/manual/none, continuous/intermittent) o the environment (e.g. home-/clinic-based, childfriendly).

\section{Search Strategy}

\section{Preliminary Research}

One reviewer conducted a preliminary exploration of the Pubmed database to assess the number of RCTs that could be included in the scoping review. The arbitrary "relevance" threshold of 10 RCTs was reached.

\section{Systematical and Complementary Research}

One reviewer systematically searched the following databases until September 2018: Pubmed, Google Scholar, CENTRAL, PEDro, ScienceDirect, ITCRP, Clinicaltrials, Open gray, Gray literature report, HAL, TEL (systematical phase). In addition, we examined the bibliographic references of reviews, systematic reviews, meta-analyses on the related subject, and included RCTs (complementary phase). We also consulted several experts who had already published on the subject (complementary phase).

\section{Search Terms}

The following keywords and Medical Subject Headings $(\mathrm{MeSH})$ terms were combined according to the specificities of each database:

(i) Pathology keywords: cerebral palsy, periventricular, leukomalacia, leucomalacia, porencephaly, congenital, hemiplegia, paresis, hemiparesis.

(ii) Population keywords: pediatric, pediatric, infant, child, preschool, adolescent, young.

(iii) Treatment keywords: intense, intensive, rehabilitation, physical and rehabilitation medicine, physical therapy specialty, occupational therapy, recovery of function, exercise movement techniques, exercise therapy, exercise, restraint, physical, task performance and analysis, nondrug prescription, constraint-induced, unilateral training, unilateral therapy, bimanual training, forced use, task oriented, task specific, repetitive task, goal oriented, goal specific, goal directed extremities, upper extremity, lower extremity.

(iv) Dosage keywords: physical therapy modalities, workload, work schedule tolerance, time, time management, time factors, dosage, dose-response, amount, period, bout, parameter, duration, programme, length of time, length of stay, hour, day, week, month, year, frequency, load, quantity, intensity.

According to the MEDLINE advanced search options, we used: the linking words "AND" and "OR", the truncating search term asterisk " " and the tags [MH], [TI] and [TIAB]. The keyword combinations corresponding to the remaining databases are available in Table S1 (online supplemental material) or on request from the corresponding author. 


\section{Study Selection}

\section{Selection Strategy}

For the systematical phase, we first collected the studies by reading the titles. Second, we removed the duplicate studies. Then, we compared the remaining studies to the eligibility criteria using successive analyses of the abstracts and full texts. As soon as their content did not meet the eligibility criteria, they were excluded without further action; studies that met all eligibility criteria were included.

For the complementary phase, we first collected the studies by reading the titles of the bibliographic references. Then, we directly compared the full-texts of the identified studies to the eligibility criteria by proceeding as above.

\section{Eligibility Criteria}

Published and gray literatures were explored without time limit.

The following inclusion criteria were applied:

- RCTs written in English or French.

- Children with USCP, aged 18 months to 19 years tolerating that up to $20 \%$ of the children included in the study were less than 18 months old - and with a motor hemiplegia as a minimum clinical criterion.

- Outcomes of upper limb functional skills and/or participation.

- Intervention and comparator groups should be exposed to similar IMRT (i.e. IMRT of same "type", or explicitly qualified as "identical", or with a synonym of "identical").

- IMRT should:

- Be consistent with one of the following IMRT types: Original-Constraint-induced movement therapy (CIMT), Modified-CIMT (mCIMT), Pediatric-CIMT ( $P$-CIMT); Bimanual Intensive Training (BIT); HandArm Bimanual Intensive Therapy (HABIT); HABITIncluding Lower Extremities (HABIT-ILE); Hybrid protocols combining two or more of the previous cited treatments; Forced-use therapy (FUT). Or, be consistent with all the following properties: 3 to 7 training days per week; from 1 to $6 \mathrm{~h}$ of rehabilitation time per training day; from 2 to 10 weeks of program duration.

- Detailed at least one of the following dosage parameters: (1) Frequency-Time, or Intensity according to (2) progressivity, (3) - restraint, or (4) - environment.

- Only differed from one group to another for at least one of the four dosage parameters above.

- Be provided or supervised at least part of the time by a rehabilitation health professional.

The following exclusion criteria were applied:

- Study analyzing the results of several RCTs, or whose design was different from an RCT.

- Children diagnosed with "profound multiples disabilities"29, or who had recently undergone surgery.

- IMRT mainly based on a computer-based training, or combined with bodysuit/garment.
- Any other element that would conflict with the above inclusion criteria.

\section{Charting the Data}

\section{Data Extraction}

One reviewer extracted data from the included studies into a structured extensive sheet. The main data collected were: authors' names; redaction/publication year; study locations; recruitment, allocation and randomization details; eligibility criteria; risks of bias; outcomes types; outcome assessment modalities and times; participant and group characteristics; intervention types; qualitative and quantitative description of intervention procedures; distinct dosage parameter(s) between the groups; dosage registration methods; main findings; result analysis methods and procedures.

\section{Collating, Summarizing, and Reporting the Results}

\section{Data Synthesis}

We presented the successive steps of the selection process in a flow chart (Figure 1).

One reviewer sorted data collected into an extensive sheet and summarized the most relevant ones in a descriptive table. The descriptive table provided the characteristics and the main findings of the studies (Table 1).

Based on psychometric studies and one systematic review $^{30-34}$ each outcome result was attributed and presented according to one of the following ICF levels: body structure, body function, activity capacity, perceived activity performance, actual activity performance, participation.

Data were summarized into three diagrams and one illustration that presented: the number of RCTs by duration of group comparisons follow-up (Figure 2); the percentage of included RCTs evaluating each ICF level (Figure 3); the number of RCTs by distinct dosage parameter(s) between the groups (Figure 4); the significant between-group differences with their ICF levels, according to the distinct dosage parameters between the groups in the included RCTs (Figure 5).

One reviewer critically analyzed data collected on the methodology and implementation of RCT protocols and summarized them in a table providing the qualitative level of evidence (Table 2). Cochrane's Risk of Bias 2.0 tool (Rob 2.0 tool, 2016) was initially used to qualitatively report the level of evidence of the included studies. Based on Peters et al.'s guidelines on scoping review ${ }^{35}$ we chose to report only the following information from the Rob 2.0 tool: randomization design, blinding nature, baseline comparability, intent to treat analysis.

\section{Results}

\section{Selection Process}

Four hundred and thirty-four studies were retained by reading the titles, 399 after removing duplicates, 104 after reading the abstracts and 16 after reading the full-texts. One additional study was included from the complementary selection phase after reading the full-texts. The distribution of studies by database and the exclusion reasons are detailed in Figure 1. 


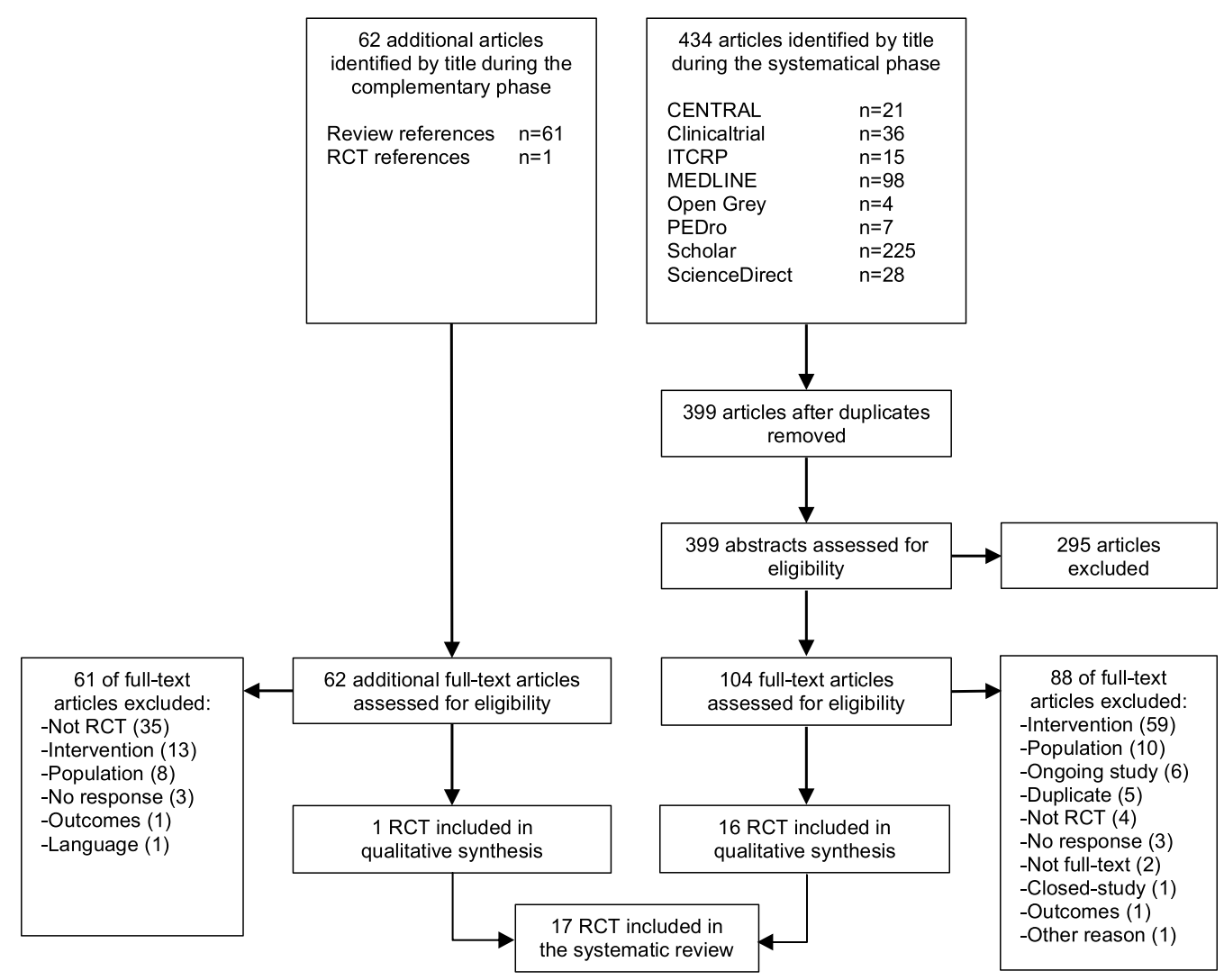

Figure 1. Flow chart of the selection process.

Legend.No response: The authors did not response to our contact or we did not find its contact; Duplicate studies deleting after the full-text reading: Duplicate studies with different titles, identified a posteriori by contacting the author.

\section{Studies Characteristics}

Seventeen RCTs were included: 7 group randomized and 10 individually randomized. Sixteen were published after 2010 and 1 before. We identified three groups of "overlapping studies", with the same original sample of children, or a subdivision of the original sample. Taking into account these overlaps, we collected 17 studies from 13 different samples of children. RCTs were conducted in America $\left(\right.$ USA $^{36-40}$, Canada $^{41}$, Brazil $\left.^{42}\right)$, Asia (South Korea ${ }^{43}$, India $^{44,45}$, $\operatorname{Iran}^{46,47}$ ), Africa $\left(\right.$ Egypt $\left.^{48}\right)$ or Europe (Netherlands ${ }^{49-51}$, England. ${ }^{52}$ )

\section{Intervention Characteristics}

The included studies provided the following treatments: $\mathrm{CIMT}^{41}, P$-CIMT ${ }^{36,37}, \mathrm{mCIMT}^{45-48,52}$, mCIMT with bimanual skills transfer phase ${ }^{46,49-51}$, HABIT $^{38-40,42,44}$, FUT $^{43}$, Intensive Motor Learning Therapy (IMLT) $)^{41,49-51}$, Intensive Motor Therapy (IMT) ${ }^{48}$ and Conventional Therapy (CT). ${ }^{43}$ HABIT programs lasted 3 to 4 weeks, $P$-CIMT 26 days, FUT and CT 6 weeks, and mCIMT, mCIMT-BIM, IMLT and IMT from 12 days to 10 weeks.

\section{Participant Characteristics}

A total of 364 children were considered, aged from 18 months to 19 years old. Various proportions of cerebral lesion side were observed in RCTs, ranging from $39 \%^{36,37}$ to $89 \%{ }^{48}$ of children with the left cerebral lesion.

\section{Outcome Characteristics}

Twenty-five outcome measurement tools were identified. Three outcomes were attributed to body structure level, one to body function, eight to activity capacity, four to actual activity performance, six to perceived activity performance, one to participation, and two were judged as categorization tools - not part of ICF levels. The rationales for allocations were presented in Table S2 (online supplemental material).

Five RCTs presented the between-group comparisons up to the post-treatment assessment ${ }^{40,43-46}$ (i.e. from 1 day to 1 week after the end of treatment depending on the studies), one RCT up to 1 month of follow-up ${ }^{36}$, two up to 1.5 months ${ }^{49,50}$, two up to 3 months ${ }^{47,48}$, seven up to 6 months ${ }^{37-39,41,42,51,52}$, and none after that. Data are summarized in Figure 2.

\section{ICF Level Exploration}

The exploration of ICF levels was presented as a percentage of the included RCTs that assessed or not each ICF level, to highlight gaps. Twelve percent (2/17) of the included RCTs assessed the body structure level ${ }^{39,50}, 12 \%(2 / 17)$ the body function ${ }^{44,46}$, $88 \%(15 / 17)$ the activity capacity ${ }^{36-39,41-43,45-52}, 65 \%(11 / 17)$ the 
Table 1. Characteristics and main findings of the included studies.

\begin{tabular}{|c|c|c|c|c|c|}
\hline Sources & Locations & Children characteristics & Treatments & $\begin{array}{l}\text { Distinct dosage parameter } \\
\text { between groups }\end{array}$ & Main findings \\
\hline $\begin{array}{l}\text { Deluca 2012; Case- } \\
\text { Smith } 2012\end{array}$ & $\begin{array}{l}\text { Virginia, } \\
\text { Ohio, } \\
\text { Alabama } \\
\text { (USA) }\end{array}$ & $\begin{array}{l}18 \text { USCP } \\
48.06 \mathrm{mo}(36-72 \mathrm{mo})^{\mathrm{a}} \\
39 \% \text { left cerebral lesion }\end{array}$ & P-CIMT & $\begin{array}{l}\text { Frequency-Time: } \\
-6 \mathrm{~h} / \mathrm{wd}, 21 \text { out of } 26 \text { days, } \\
\text { total of } 126 \mathrm{~h} \text { vs. } \\
-3 \mathrm{~h} / \mathrm{wd}, 21 \text { out of } 26 \text { days, } \\
\text { total of } 63 \mathrm{~h}\end{array}$ & $\begin{array}{l}\text { No significant between-group difference after } 1 \\
\text { month (Deluca et al. 2012) and } 6 \text { months (Case- } \\
\text { Smith et al. 2012). }\end{array}$ \\
\hline Brandão 2017 & $\begin{array}{l}\text { Belo } \\
\text { Horizonte } \\
\text { (Brazil) }\end{array}$ & $\begin{array}{l}20 \text { USCP } \\
9.09 y \text { and } 8.60 y(4-12 y)^{a} \\
56 \% \text { left cerebral lesion }\end{array}$ & HABIT & $\begin{array}{l}\text { Frequency-Time: } \\
-1 \times 90 \mathrm{~h} \text { of intervention } \\
(6 \mathrm{~h} / \mathrm{wd}, 1 \text { block of } 15 \mathrm{~d}, \text { no } \\
\text { break) vs. } \\
-2 \times 45 \mathrm{~h} \text { of intervention } \\
\text { ( } 6 \mathrm{~h} / \mathrm{wd}, 2 \text { blocks of } 7.5 \mathrm{~d}, \\
6 \mathrm{mo} \text { of break) }\end{array}$ & $\begin{array}{l}\text { No significant between-group difference after } \\
1 \times 45 \mathrm{~h}, 2 \times 45 \mathrm{~h} \text { or } 1 \times 90 \mathrm{~h} \text { of HABIT. Calculation of } \\
\text { the power required to find significant between- } \\
\text { group interactions: requiring } 56 \text { to } 66 \text { children. }\end{array}$ \\
\hline Brandão 2014 & $\begin{array}{l}\text { New York } \\
\text { (USA) }\end{array}$ & $\begin{array}{l}22 \text { USCP; } \\
8.5 y \text { and } 8.3 y(6-13 y)^{\mathrm{a}} \\
70 \% \text { left cerebral lesion }\end{array}$ & HABIT & $\begin{array}{l}\text { Intensity progressivity: } \\
\text { - Structured (increasing } \\
\text { complexity, shaping, goal- } \\
\text { training) vs. } \\
\text { - Unstructured } \\
\text { ("enjoyable" and "playful } \\
\text { context") }\end{array}$ & $\begin{array}{l}\text { Structured HABIT showed a better pre-post } \\
\text { treatment improvement than Unstructured } \\
\text { HABIT in perceived activity performance of } \\
\text { functional goals (i.e. COPM-Performance); not } \\
\text { retained after } 6 \text { months. } \\
\text { No significant between-group difference in } \\
\text { other outcomes. }\end{array}$ \\
\hline Friel 2016 & $\begin{array}{l}\text { New York } \\
\text { (USA) }\end{array}$ & $\begin{array}{l}20 \text { USCP }(18 \text { randomized }) \\
9.9 y \text { and } 8.9 y(N I)^{\mathrm{a}} \\
60 \% \text { left cerebral lesion }\end{array}$ & HABIT & $\begin{array}{l}\text { Intensity progressivity: } \\
\text { Identical to Brandão et al. } \\
2014\end{array}$ & $\begin{array}{l}\text { Only Structured HABIT showed increases of the } \\
\text { affected hand motor map and motor evoked } \\
\text { potentials amplitudes; greater improvements in } \\
\text { JTHF and COPM-Performance were associated } \\
\text { with larger hand motor map expansions after } 6 \\
\text { months. No significant between-group } \\
\text { difference in other outcomes. }\end{array}$ \\
\hline Hung 2017 & $\begin{array}{l}\text { New York } \\
\text { (USA) }\end{array}$ & $\begin{array}{l}22 \text { USCP } \\
8.5 y \text { and } 8.3 y(6-13 y)^{a} \\
70 \% \text { left cerebral lesion }\end{array}$ & HABIT & $\begin{array}{l}\text { Intensity progressivity: } \\
\text { Identical to Brandão et al. } \\
2014\end{array}$ & $\begin{array}{l}\text { "Only the Structured Practice Group showed } \\
\text { better movement quality [, less variable,] with } \\
\text { less trunk involvement and greater elbow } \\
\text { excursion than the Unstructured Practice } \\
\text { Group". }\end{array}$ \\
\hline Kumar 2017 & $\begin{array}{l}\text { Aurangabad } \\
\text { (India) }\end{array}$ & $\begin{array}{l}34 \text { USCP } \\
6.67 y \text { and } 6.56 y(4-8 y)^{a} \\
40 \% \text { left cerebral lesion }\end{array}$ & HABIT & $\begin{array}{l}\text { Intensity progressivity: } \\
\text { - Increasing complexity, } \\
\text { different manipulation } \\
\text { modalities vs. } \\
\text { - Stable complexity, } \\
\text { constant manipulation } \\
\text { modalities }\end{array}$ & $\begin{array}{l}\text { We did not consider between-group data } \\
\text { because (1) they were based only on the post- } \\
\text { treatment scores comparison; (2) MAS and } \\
\text { MACS data were treated as a "continuous } \\
\text { quantitative variables" when they were } \\
\text { "quantitative categorical variables" with a non- } \\
\text { equivalent scoring interval; (3) were not } \\
\text { confronted to their minimal clinically important } \\
\text { difference. }\end{array}$ \\
\hline Sabour 2013 & $\begin{array}{l}\text { Tehran } \\
\text { (Iran) }\end{array}$ & 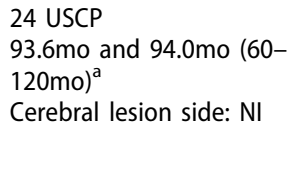 & $\begin{array}{l}\text { mCIMT-BIM vs. } \\
\text { mCIMT }\end{array}$ & $\begin{array}{l}\text { Intensity restraint: } \\
\text { - Rehabilitation } 6 \mathrm{~h} / \mathrm{wd} \text { (i.e. } \\
3 \mathrm{~h} \text { with sling restraint, } 3 \mathrm{~h} \\
\text { without) vs. } \\
\text { - Rehabilitation } 6 \mathrm{~h} / \mathrm{wd} \\
\text { with a sling restraint }\end{array}$ & $\begin{array}{l}\text { We did not consider between-group data } \\
\text { because they were based only on the post- } \\
\text { treatment scores comparison. }\end{array}$ \\
\hline Kirton 2016 & $\begin{array}{l}\text { Calgary } \\
\text { (Canada) }\end{array}$ & $\begin{array}{l}45 \text { USCP } \\
10.34 y \text { and } 10.57 y(6- \\
19 y)^{a} \\
56 \% \text { left cerebral lesion }\end{array}$ & $\begin{array}{l}\text { CIMT } \\
\text { vs. IMLT }\end{array}$ & $\begin{array}{l}\text { Intensity restraint: } \\
\text { - Time restrained: } 90 \% \text { of } \\
\text { waking hours vs. } \\
\text { - Not restrained }\end{array}$ & $\begin{array}{l}\text { The CIMT group showed a better improvement } \\
\text { than IMLT group in the perceived activity } \\
\text { performance (i.e. COPM-Satisfaction) after } 6 \\
\text { months. Only the CIMT group reached the COPM } \\
\text { clinically significant gains after } 6 \text { months. }\end{array}$ \\
\hline Christmas 2018 & $\begin{array}{l}\text { Birmingham } \\
\text { (England) }\end{array}$ & $\begin{array}{l}62 \text { USCP } \\
31.5 \mathrm{mo} \text { and } 29.0 \mathrm{mo}(18- \\
48 \mathrm{mo})^{\mathrm{a}} \\
\text { Cerebral lesion side: } \mathrm{NI}\end{array}$ & mCIMT & $\begin{array}{l}\text { Intensity restraint: } \\
\text { - Continuous short-arm } \\
\text { semi-rigid restraint }(24 \mathrm{~h} / \mathrm{d} \\
\text { restrained) vs. } \\
\text { - Intermittent manual } \\
\text { holding restraint (total } \\
\text { restrained: } 1 \mathrm{~h} / \mathrm{d})\end{array}$ & $\begin{array}{l}\text { The continuous restrained } \mathrm{mCIMT} \text { was } \\
\text { associated with a longer daily therapy time } \\
\text { delivered than the Intermittent holding restraint } \\
\text { (i.e. } 60 \text { vs. } 30 \text { minutes). No significant between- } \\
\text { group difference in other outcomes. }\end{array}$ \\
\hline Rostami 2012 & $\begin{array}{l}\text { Ahvaz } \\
\text { (Iran) }\end{array}$ & $\begin{array}{l}14 \text { USCP } \\
74 \mathrm{mo}(49-100 \mathrm{mo})^{\mathrm{a}} \\
\text { Cerebral lesion side: } \mathrm{NI}\end{array}$ & mCIMT & $\begin{array}{l}\text { Intensity environment: } \\
\text { Home-based rehabilitation } \\
(0 \% \text { at the clinic) vs. } \\
\text { Clinic-based rehabilitation } \\
\text { (0\% at home) }\end{array}$ & $\begin{array}{l}\text { The home-based mCIMT showed a better } \\
\text { improvement than the clinic-based group in the } \\
\text { global activity capacity after } 3 \text { months. No } \\
\text { significant between-group difference in other } \\
\text { outcomes after } 3 \text { months. }\end{array}$ \\
\hline Chopra 2013 & $\begin{array}{l}\text { New Delhi } \\
\text { (India) }\end{array}$ & $\begin{array}{l}30 \text { USCP } \\
5.95 y(4-8 y)^{a} \\
57 \% \text { left cerebral lesion }\end{array}$ & mCIMT & $\begin{array}{l}\text { Intensity environment: } \\
\text { - Activities therapist- } \\
\text { supervised \& guided vs. } \\
\text { - Activities parents- } \\
\text { supervised, therapist- } \\
\text { guided }\end{array}$ & $\begin{array}{l}\text { We did not consider pre-post treatment data } \\
\text { and between-group data because: (1) no } \\
\text { standard deviation was provided; (2) the } \\
\text { between-group difference was based only on } \\
\text { the comparison of post-treatment scores. }\end{array}$ \\
\hline Sung 2005 & $\begin{array}{l}\text { Asan } \\
\text { (South } \\
\text { Korea) }\end{array}$ & $\begin{array}{l}31 \text { USCP } \\
33.2 \mathrm{mo} \text { and } 43.2 \mathrm{mo}(\mathrm{NI})^{\mathrm{a}} \\
68 \% \text { left cerebral lesion }\end{array}$ & $\begin{array}{l}\text { FUT } \\
\text { vs. CT }\end{array}$ & $\begin{array}{l}\geq 3 \text { distinct dosage } \\
\text { parameters (Type } \\
\text { distinction) }\end{array}$ & $\begin{array}{l}\text { The FUT group showed better pre-post } \\
\text { treatment improvements than the CT group in } \\
\text { unimanual activity capacity, and global actual } \\
\text { activity performance. }\end{array}$ \\
\hline
\end{tabular}


Table 1. (Continued).

\begin{tabular}{|c|c|c|c|c|c|}
\hline Sources & Locations & Children characteristics & Treatments & $\begin{array}{c}\text { Distinct dosage parameter } \\
\text { between groups }\end{array}$ & Main findings \\
\hline $\begin{array}{l}\text { Aarts 2010, 2011; } \\
\text { Geerdink } \\
2013\end{array}$ & $\begin{array}{l}\text { Ubbergen } \\
\text { (Netherlands) }\end{array}$ & $\begin{array}{l}52 \text { USCP } \\
\text { Mean age: } \mathrm{NI}(2.5 \text { to } 8 \mathrm{y})^{\mathrm{a}} \\
44 \% \text { left cerebral lesion }\end{array}$ & $\begin{array}{l}\text { mCIMT-BIM } \\
\text { vs. IMLT }\end{array}$ & $\begin{array}{l}\geq 3 \text { distinct dosage } \\
\text { parameters (Type } \\
\text { distinction) }\end{array}$ & $\begin{array}{l}\text { The mCIMT-BIT group showed better } \\
\text { improvements than the IMLT group in the } \\
\text { bimanual actual activity performance, and } \\
\text { perceived activity performance of bimanual } \\
\text { tasks and functional goals after } 8 \text { weeks (Aarts } \\
\text { et al. 2010) or } 6 \text { months (Geerdink et al. 2013). } \\
\text { No significant between-group difference after } 8 \\
\text { weeks (Aarts et al. 2010, 2011) or } 6 \text { months } \\
\text { (Geerdink et al. 2013) in other outcomes. }\end{array}$ \\
\hline El-Kafy 2014 & $\begin{array}{l}\text { Le Caire } \\
\text { (Egypt) }\end{array}$ & $\begin{array}{l}30 \text { USCP } \\
6.0 y \text { and } 6.2 y(4-8 y)^{a} \\
89 \% \text { left cerebral lesion }\end{array}$ & $\begin{array}{l}\mathrm{mCIMT} \\
\text { vs. IMT }\end{array}$ & $\begin{array}{l}\geq 3 \text { distinct dosage } \\
\text { parameters (Type } \\
\text { distinction) }\end{array}$ & $\begin{array}{l}\text { The mCIMT group showed better improvements } \\
\text { than the IMT group in isokinetic shoulder flexors } \\
\text { performance and bimanual activity capacity } \\
\text { after } 3 \text { months. No significant between-group } \\
\text { difference in other outcomes. }\end{array}$ \\
\hline
\end{tabular}

USCP: Unilateral Spastic Cerebral Palsy

${ }^{a}$ Mean age (range); NI: No Information; mo: month; y: year; wd: weekday; h: hour; CIMT: Constraint Induced Movement Therapy; P-CIMT: Pediatric-Constraint Induced Movement Therapy; mCIMT: modified Constraint Induced Movement Therapy; BIM: Bimanual skills Transfer phase; HABIT: Hand Arm Bimanual Intensive Therapy; FUT: Forced Use Therapy; IMLT: Intensive Motor Learning Therapy; IMT: Intensive Motor Therapy; CT: Conventional Therapy; COPM: Canadian Occupational Performance Measure; MAS: Modified Aschworth Scale; MACS: Manual Ability Classification System; JTTHF: Jebsen-Taylor Test of Hand Function

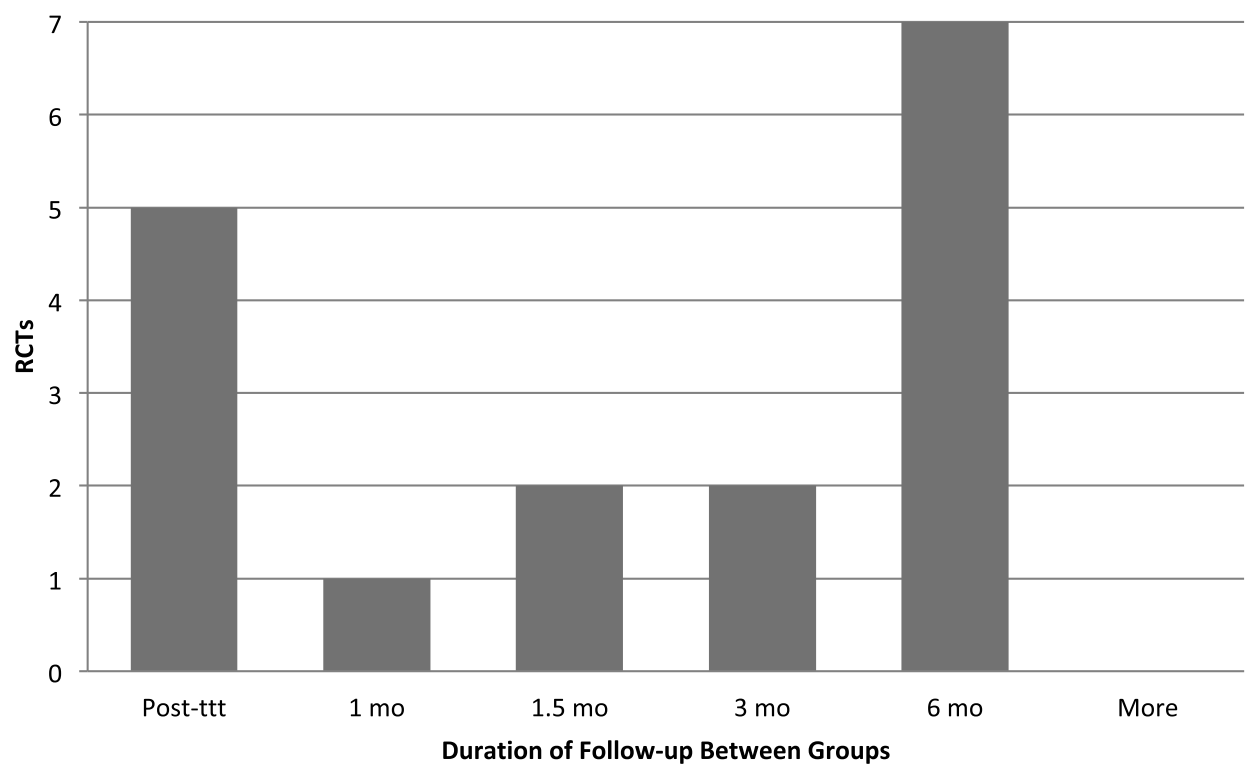

Figure 2. Number of studies by the duration of groups comparison follow-up.

Legend.Post-treatment: Hung (2017); Kumar (2017); Sabour (2013); Chopra (2013); Sung (2005) 1 month: Deluca (2012)1.5 months: Aarts (2010, 2011) 3 months: Rostami (2012); El-Kafy (2014) 6 months: Case-Smith (2012); Brandão (2014, 2017); Friel (2016); Kirton (2016); Christmas (2018); Geerdink (2013)

perceived activity performance $\mathrm{e}^{36-39,41,42,44,47,49,51,52}, 71 \%(12 / 17)$ the actual activity performance $36-43,48,49,51,52$, and $12 \%(2 / 17)$ the participation of children. ${ }^{41,52}$ No RCTs explored all ICF levels. In contrast, with regard to child samples, one sample was examined by three RCTs ${ }^{38-40}$, resulting in a more complete exploration of ICF levels: body structure, activity capacity, actual and perceived activity performance. Data are summarized in Figure 3.

\section{Distinct Dosage Parameters between Groups}

The dosage was presented through the number of RCTs that allowed the dosage parameters of the treatments to be questioned individually. Three RCTs isolated relatively the frequency-time parameter $^{36,37,42}$, four RCTs the intensity-progressivity parameter $^{38-40,44}, 3$ RCTs the intensity-restraint parameter ${ }^{41,46,52}$, and two RCTs the intensity-environment parameter. ${ }^{45,47}$ Five RCTs also compared interventions that differed in three or more dosage parameters. ${ }^{43,48-51}$ The rest time given to children was neither studied nor reported. Data are summarized in Figure 4.

\section{Findings of Included Studies}

Between-group differences were not considered for three RCTs $^{44-46}$ because they were judged irrelevant as they were calculated solely on the basis of the comparison of posttreatment scores.

The majority of the remaining RCTs showed statistically significant between-group differences $(10 / 13)$ in at least one 


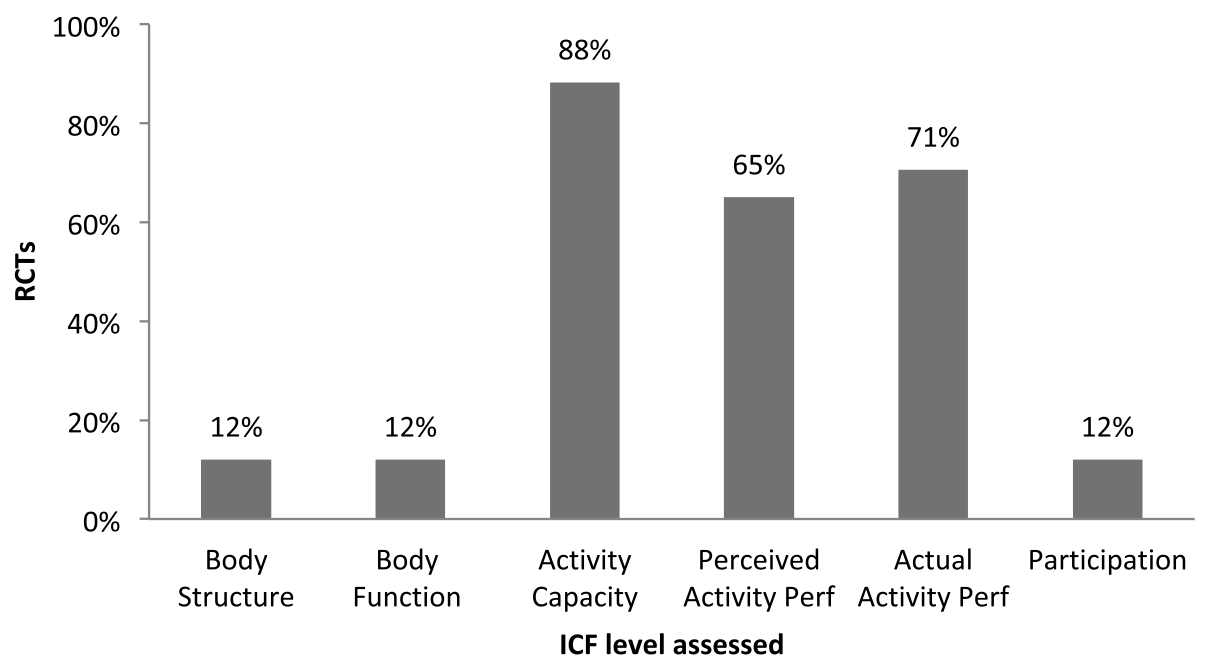

Figure 3. Percentage of included studies assessing each ICF level.

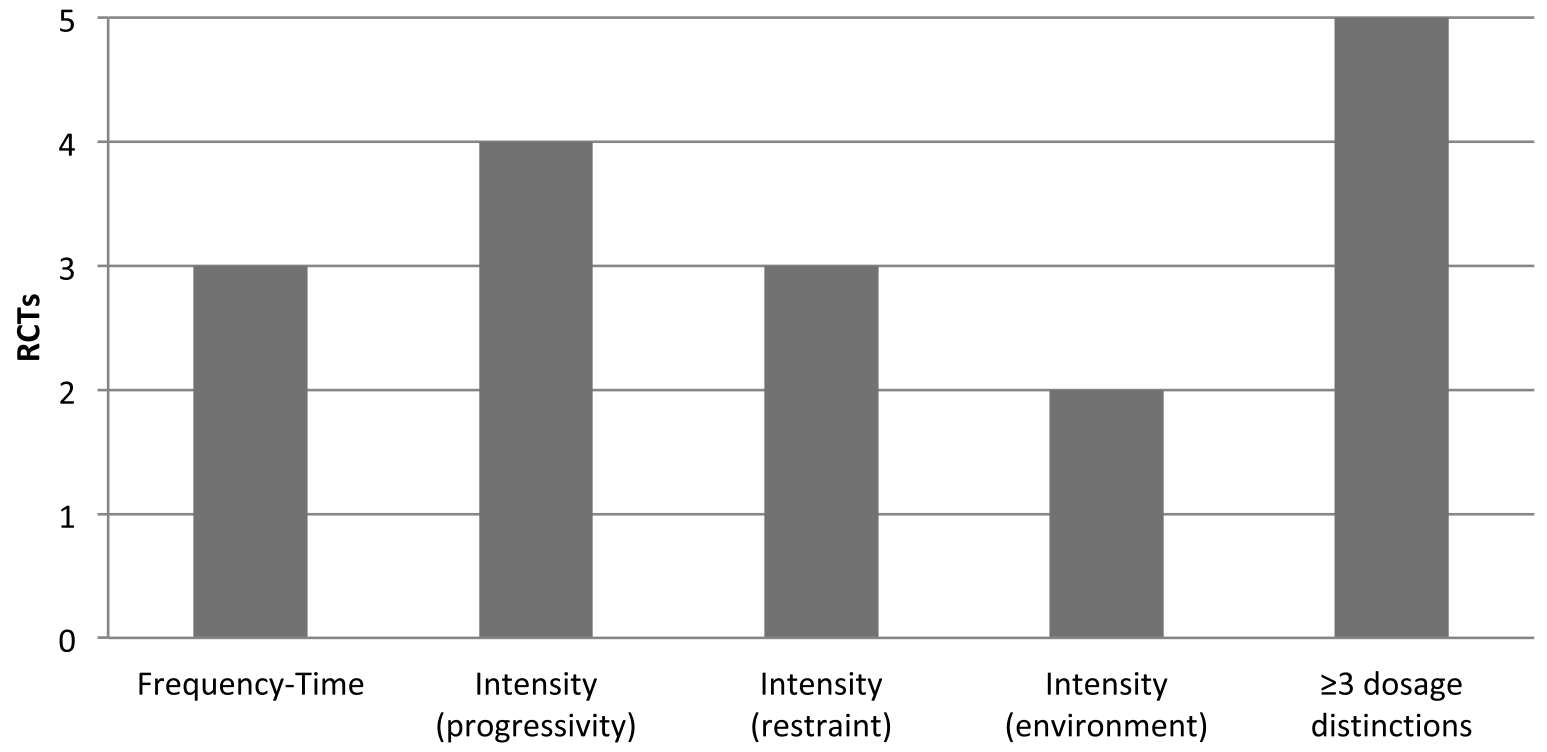

The distinct dosage parameter between groups

Figure 4. Number of RCTs by distinct dosage parameter(s) between the groups.

outcome measure ${ }^{38-41,43,47-51}$ for various types of treatment provided. Three-fourths of the RCTs isolating the intensityprogressivity parameter showed significant between-group differences in the body structure ${ }^{39}$, and the actual ${ }^{40}$ and perceived $^{38}$ activity performance up to 6 months of followup. One-third of the RCTs isolating the intensity-restraint parameter showed a between-group difference in the perceived activity performance up to 6 months of follow-up. ${ }^{41}$ One-half of the RCTs isolating the intensity-environment parameter showed a between-group difference in the activity capacity up to 3 months of follow-up. ${ }^{47}$ The three RCTs comparing interventions that differed in FrequencyTime $\mathrm{T}^{36,37,42}$ did not find a significant between-group difference, although the groups showed similar activity improvements. They investigated the management of daily rehabilitation time, or the continuous/per block rehabilitation schedule, for up to 6 months of follow-up. The five
RCTs comparing interventions that differed in three or more dosage parameters showed between-group differences in all ICF levels assessed ${ }^{43,48-51}$; excepting the following ones: body structure (no significant difference), and participation (not assessed). Data are summarized in Figure 5.

It should be noted that one RCT comparing HABIT that differed in intensity-progressivity showed a likely benefit of the "Structured Practice Group" by a relationship between body structure and activity capacity and actual performance after 6 months of follow-up ${ }^{39}$ - greater improvements in JTTHF and COPM-Performance were associated with larger hand motor map expansions.

\section{Level of Evidence}

The level of evidence criteria revealed that $71 \%(12 / 17)$ of the RCTs had blind assessors ${ }^{37-39,41,42,46-50,52}$ and 29\% (5/17) did not 


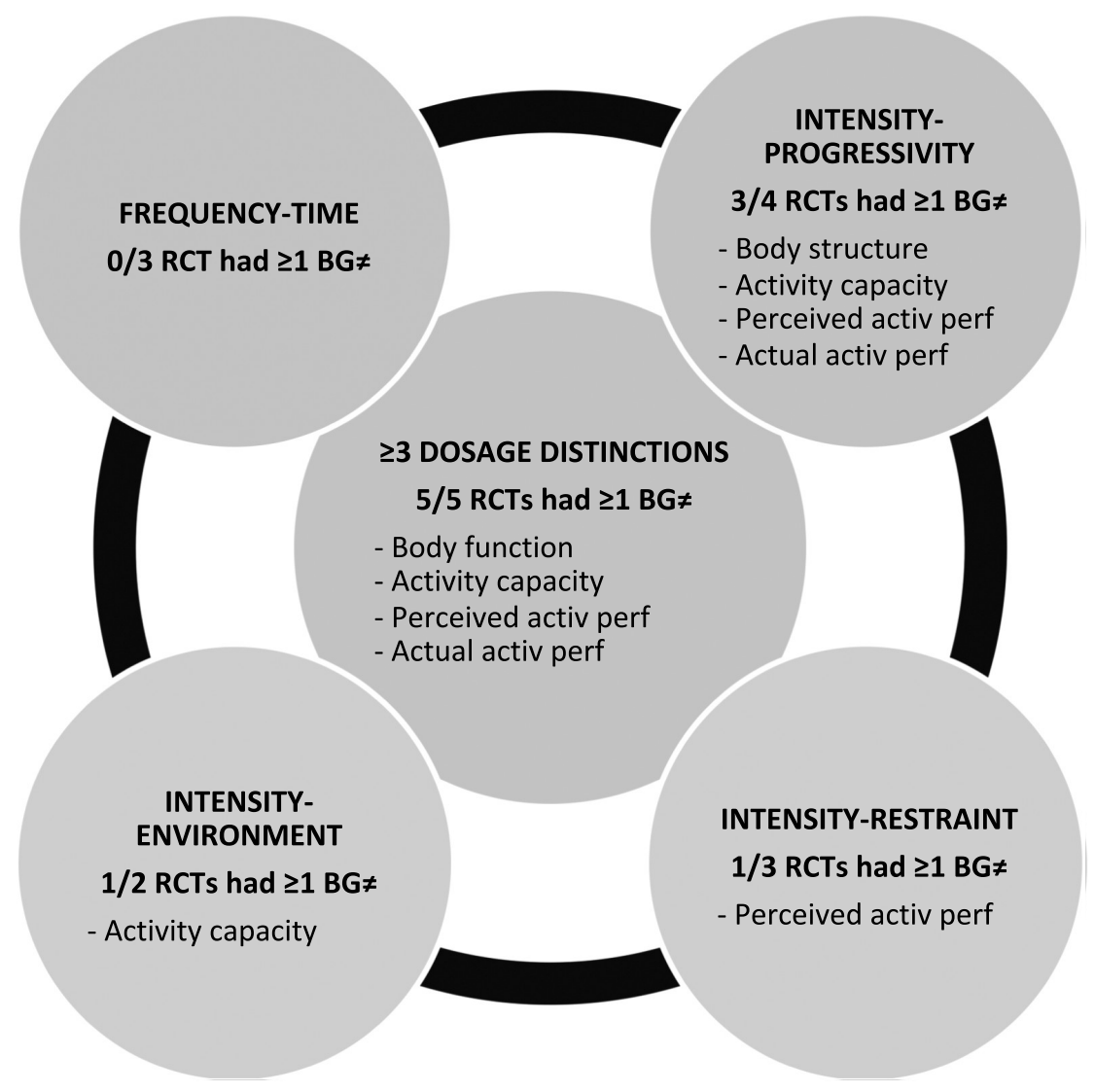

Figure 5. The significant between-group differences with their ICF levels, according to the distinct dosage parameters between groups in the included studies. Legend.Frequency-Time parameter: Deluca (2012); Case-Smith (2012); Brandão (2017)Intensity-progressivity parameter: Brandão (2014); Friel (2016); Hung (2017); Kumar (2017)Intensity-restraint parameter: Sabour (2013); Kirton (2016); Christmas (2018)Intensity-environment parameter:Rostami (2012); Chopra (2013) $\geq 3$ dosage parameters distincts: Sung (2005); Aarts (2010, 2011); Geerdink (2013); El-Kafy (2014)

Table 2. Level of evidence of the included studies.

\begin{tabular}{lllll}
\hline Source & \multicolumn{1}{c}{ Randomization design } & Blinding & BC & ITT \\
\hline Deluca 2012 & Group & Assessor* & No & Yes \\
Case-Smith 2012 & Group & Assessor* & No & No \\
Brandão 2017 & Group stratified by age \& JTTHF & Assessor* & Yes & No \\
Brandão 2014 & Group stratified by age \& JTTHF & Assessor* & Yes & No \\
Friel 2016 & Group stratified by age \& JTTHF & Assessor* & Yes & No \\
Hung 2017 & Group stratified by age \& JTTHF & $\mathrm{NI}$ & Yes & No \\
Kumar 2017 & Individual & $\mathrm{NI}$ & Yes & No \\
Sabour 2013 & Individual & Assessor & $\mathrm{NI}$ & $\mathrm{Nl}$ \\
Kirton 2016 & Group by age & Assessor* & Yes & Yes \\
Christmas 2018 & Group stratified by center & Assessor* & $\mathrm{No}$ & $\mathrm{No}$ \\
Rostami 2012 & Individual & Assessor* & Yes & $\mathrm{Nl}$ \\
Chopra 2013 & Individual & $\mathrm{NI}$ & $\mathrm{NI}$ & $\mathrm{Nl}$ \\
Sung 2005 & Individual & $\mathrm{NI}$ & Yes & $\mathrm{Nl}$ \\
Aarts 2010 & Individual & Assessor* & Yes & No \\
Aarts 2011 & Individual & Assessor & Yes & No \\
Geerdink 2013 & Individual & $\mathrm{NI}$ & Yes & No \\
El-Kafy 2014 & Individual & Assessor & Yes & No \\
\hline
\end{tabular}

JTTHF: Jebsen-Taylor Test of Hand Function; *Assessor was not blind in the case of self-evaluation of the child or parents; BC: Baseline Comparability; ITT: Intent To Treat Analysis; Nl: No Information

provide sufficient information. ${ }^{40,43-45,51} 71 \%$ (12/17) of the RCTs presented between-group baseline comparability ${ }^{38-41,43,44,47-51}$, while $18 \%(3 / 17)$ presented pre-treatment between-group differences of the upper limb functioning ${ }^{36,37}$, or the age $e^{52}$, and $12 \%$ $(2 / 17)$ did not provide sufficient information. ${ }^{45,46}$ Twelve percent $(2 / 17)$ of the RCTs actually performed an Intent To Treat Analysis $^{36,41}$ - "subjects allocated to a treatment group [...] followed, assessed and analysed as members of the treatment group irrespective of their compliance with the planned course of treatment" (https://www.thefreedictionary.com/). Sixty-five percent $(11 / 17)$ did not meet the previous ITT definition. ${ }^{37-40,42,44,48-52}$ $24 \%(4 / 17)$ did not provide sufficient information to judge the data analysis. ${ }^{43,45-47}$ The correspondence between the studies and the methodological quality criteria is presented in Table 2.

\section{Discussion}

\section{Summary of Findings}

To our knowledge, this scoping review is the first to gather only RCTs that allowed the dosage parameters, of IMRT of the upper limbs provided to children with USCP, to be questioned individually.

The extent exploration of literature databases led us to include $17 \mathrm{RCTs}^{36-52}$ with heterogeneous methodological quality, ranging from very low to relatively high.

Some inconsistencies between clinical issues and research protocols are identified; in particular the too short follow-up of the children's outcome evolutions, the lack of assessment of children's participation, and the links between the evolutions of the different ICF levels.

Doubts are expressed about the relevance of conducting a meta-analysis regarding the consequent presence of these selection, attrition, interpretation, and confusion biases. The main findings should, therefore, be qualified in light of this information. 


\section{Strengths and Weaknesses of the Review}

In order to question the consistency of the method with the author's objectives, we considered it relevant to focus on a priori high level of evidence study designs: RCTs, which are the standard of excellence for comparing the effects of several treatment modalities. Also, we conducted preliminary research that reached the arbitrary threshold of 10 RCTs for relevance.

The eligibility criteria focused only on children with USCPs, which reduced the confounding factors involved in the variability of the $\mathrm{CP}$ subtypes' specific disability profiles. ${ }^{2}$ Nevertheless, some uncontrollable ones still prevented us from exclusively questioning the impact of each dosage parameter on children's functional and participation skills.

The dosage parameter terminology was based on a critical terminological framework of the dosage developed from standardized and reference model $\mathrm{s}^{23,26-28}$ ensuring transparency and clear peer understanding. Our critique mainly consisted in dividing the "intensity" parameter into three sub-groups to distance us from the Kolobe et al. definition from which Cope and Mohn-Johnsen's systematic review did not find a study. ${ }^{24}$

The systematic literature exploration permitted to include the more recent randomized-controlled literature on the subject $^{40,42,44,52}$ and the previous RTCs ${ }^{38,39,41,43,45-48}$ that were not included in the last two reviews on dosage parameters. ${ }^{17,24}$

Only studies written in French or English were reviewed, but this could be offset by the extensive use of English in cerebral palsy research. We could not ignore the reviewer's subjectivity in assigning the "distinction of dosing parameters" to the groups, based on the reporting of dosage in the protocols by the RCT authors. On the other hand, we tried to be transparent about the method and terminology used.

\section{Interpretation of Findings}

\section{Level of Evidence}

The level of evidence is relatively homogeneous due to the blindness of the evaluators, the presence of baseline comparability and the lack of ITT analyses performed. The randomization design is equally distributed between group-randomization (47\% of RCTs ${ }^{36-42,52}$ ) and individual-randomization $(53 \%$ of $\left.\mathrm{RCTs}^{43-51}\right)$. The least satisfied methodological quality criterion is, therefore, the ITT analysis (Table 2). The ITT analysis depends on many uncontrollable factors (e.g. patient adherence to the rehabilitation program, direct or secondary side effects related to the intervention, unexpected events in daily life) fostered by the multidimensional nature of IMRT. Indeed, IMRT involved: multiple actors (e.g. children, parents, teachers, carers, care-givers, students), in multiple places (e.g. clinic, home, school), requiring a significant social and temporal commitment (e.g. 24 hours/day of restrained time). It is therefore often complicated to ensure ITT analysis due to frequent loss of follow-up; increasing complexity with increasing followup time.

The lack of consensus on the ITT definition leads in part to a bias in the reports. Many authors reported that they carry out an ITT analysis while the study showed missing outcome data and/or loss of child follow-up. ${ }^{37-40,42,44,48-52}$ However, alternatives exist to limit the impact of the attrition bias such as interpolating missing data with known data, as Friel et al. did using the group average. ${ }^{39}$

\section{Inconsistencies between Clinical Issues and Research Protocols}

Follow-up - We found some inconsistencies between the very long-term clinical challenges, induced by the lifelong motor disabilities of $\mathrm{CP}^{2}$, and the too short follow-up of the RCTs analyzed. Indeed, $59 \%$ of RCTs (10/17) stopped the assessments before 13 weeks of follow-up $37,40,43-50$, of which $50 \%$ (5/10) stopped them at the post-treatment assessment point. ${ }^{40,43-46}$ However, since the 2013 Novak et al.'s recommendations ${ }^{12}$ that "additional studies that evaluate long-term outcomes are necessary [because] long-term outcome data are essential for costing and optimizing the outcomes", only $2 / 6$ of the RCTs published after 2015 stopped follow-up before 6 months ${ }^{40,44}$; including one that supplemented a longer RCT protocol assessing children up to 6 months of follow-up. ${ }^{38-40}$ But keeping a critical eye, no studies compared data between groups after this 6-month followup point. The increasing relationship between the prevalence of confounding factors and the duration of follow-up ${ }^{2}$ could partly explain this research gap.

Outcomes - The exploration of the diverse ICF levels appears very heterogeneous, the activity level being largely questioned when only $12 \%$ of the RCTs (2/17) assessed the body structure ${ }^{39,50}$, the body function ${ }^{44,46}$, or the participation $^{41,52}$ (Figure 3). One explanation could be that tools commonly considered as assessing the children's participation more often assess the perceived activity performance (e.g. COPM, ABILHAND-Kids, or GAS $S^{38,39,41,42,49,51}$ ) through tasks that are too limited to be considered representative of the participation in daily life, as noted by Lemmens et al. (2012). ${ }^{34}$ Panteliadis et al. $(2018)^{2}$ qualify latter ones as "patient-focused tools" and recommend to combine "focused goal assessment with a wider scan of [Quality of Life]".

It may also be regretted that there are no RCT protocols combining assessment of the body structure level with other ICF levels. Friel et al. $(2016)^{39}$ were one of the firsts to assess the "critical ingredients that drive motor cortex plasticity [in association] with bimanual training" through the activity ICF level. They obtained encouraging but not statistically significant results between groups. In addition, several recent longitudinal trials initiatives questioning the intensive rehabilitation of children with $\mathrm{CP}$ in this way are to be noted $^{53,54}$ thus opening up this interdisciplinary aspect of research.

\section{Meta-analysis Not Relevant}

We are reluctant to conduct a meta-analysis faced with the heterogeneity in the levels of evidence of RCTs (Table 2) and the relative lack of RCTs per dosage parameter (Figure 4) and the persistence of many uncontrollable confounding factors (detailed in the level of evidence paragraph). Other confounding factors justified our choice: (1) the heterogeneity of geographical situations covering four continents, which results in cultural, care accessibility, socio-economic levels, and many other secondary 
differences; (2) the heterogeneity of participants' characteristics (e.g. large age range, different cerebral lesion side distributions between studies); (3) the heterogeneity of interventions provided (e.g. Various IMRT types between studies, non-uniformity in the management of dosage parameters between studies, the lack of transparency of the environment parameter ${ }^{22}$ ) .

\section{Main Findings}

For the same reasons that a meta-analysis is not relevant, the main findings of the studies should be tempered in light of the potential selection, attrition, interpretation, and confusion biases detailed in Discussion. Therefore, the main results presented in Figure 5 mainly map and illustrate the authors' interests and research gaps.

\section{Implications for Practice}

As presented above in the Main findings chapter, our scoping review reminds us of the need to maintain a critical mind aware of the possible cognitive and methodological biases with which we are constantly confronted.

Standardized evidence-based protocols (e.g. CIMT, mCIMT, $P$-CIMT, HABIT, mCIMT-BIT) appear to be superior to conventional therapy or alternative intensive rehabilitation treatments (IMLT, ITM). Their extensive research may have gradually led to optimize their dosage management leading to standardized guidelines. ${ }^{55-57}$

In addition, the presentation of the main findings of the RCTs according to the dosage parameter distinctions between groups reveals some encouraging results. Despite the management of the Frequency-Time parameter, daily rehabilitation time or the continuous/blocks rehabilitation schedule would not be beneficial to a group ${ }^{36,37,42}$; the management of the progression of intensity by applying the principles of motor learning seems linked to the improvement of many ICF levels. ${ }^{38-40,44}$ The management of restraint time or the nature of restraint does not seem crucial and presents heterogeneous results. ${ }^{41,46,52}$ The IntensityEnvironment parameter is poorly explored ${ }^{45,58}$, and difficult to isolate because of its uncontrollable multidimensional nature. ${ }^{22}$

It is therefore probably premature to recommend that professionals develop their own intensive rehabilitation programs by managing each dosage parameter individually.

However, we strongly recommend, first, that more IMRT be implemented initially based on standardized evidencebased IMRT and, second, that they be managed by the dosage parameter to adapt the original protocols to context-induced specificities and the expectations of children and parents.

Thus, our results are in line with the current systematic literature that recommended IMRT to promote the overall improvement of upper-limb motor function and participation of children with USCP by combining the four dosage parameters' managements as follows:

(1) Frequency-Time: "60 or even 90 hours of continuous intensive rehabilitation" seems correlated to at least 6 months of maintaining functional benefits. ${ }^{11,59}$

(2) Intensity-progressivity: To privilege motor learning principle implementation (i.e. shaping, repetition, progressive difficulty, individualized goal-oriented therapy, child-friendly context). ${ }^{12}$

(3) Intensity-restraint: At dose-equivalent, no differences between constrained versus unconstrained therapies are observed. ${ }^{13,14}$

(4) Intensity-environment: To choose between a home-/clinical-rehabilitation program according to the family contexts and objectives; to integrate into our decision, the ethical benefit of promoting accessibility to the intensive rehabilitation programs by implementing in-groups children programs as recommended in a recent systematic review. $^{16}$

\section{Implications for Research}

In light of our observations, greater transparency by the authors on the definition of ITT analysis and sincerity in the analysis of the data produced could easily improve the quality and transversality of the sharing of scientific documents. Interpolation of known values to the missing outcome data could also prevent the attrition bias repercussions.

Given the lack of RCTs allowing to question each of the dosage parameters, especially the Intensity-environment parameter, particular attention in the inclusion criteria could easily limit this gap: by providing the same type of IMRT to both groups; interventions differing only by a single dosage parameter.

Again, we encourage RCTs to evaluate, through a followup of at least 6 months, the multiple ICF levels and to specifically combine body structure assessments - neuroimaging outcomes - with other functional and participation ones. For the participation level, appropriate outcome measures of the quality of life should be used (e.g. PedsQL, KIDSCREEN, CP QOL-Child) in combination with goal assessments (e.g. COPM, GAS) as recommended by Panteliadis et al. ${ }^{2}$

Finally, the authors never detailed the rest period granted to children. This illustrates the need for authors to further detail their research protocols and dosage parameters using standardized and transparent terminology.

This last observation raises several questions that may be the subject of future research. In effect, USCP induces several biopsycho-social repercussions in children and their families: What are these repercussions? What are their impacts on (intensive) rehabilitation? What are the specific considerations to be taken into account when adapting rehabilitation to the child (and no longer to adapting the child to rehabilitation)?

\section{Acknowledgments}

We thank Jean-Philippe Regnaux for his methodological expertise and Katherine Heidrich for her expertise in proofreading. No ethical review was required for this study. The authors have stated that they had no interests which might be perceived as posing a conflict or bias.

\section{Disclosure statement}

No potential conflict of interest was reported by the authors.

\section{ORCID}

Lucas Ravault (D) http://orcid.org/0000-0002-6020-3542 


\section{References}

1. Sellier E, Platt MJ, Andersen GL, Krägeloh-Mann I, De La Cruz J, Cans C. Decreasing prevalence in cerebral palsy: a multi-site European population-based study, 1980 to 2003. Dev Med Child Neurol. 2016;58:85-92. doi:10.1111/dmcn.12865.

2. Panteliadis C. Cerebral palsy: a multidisciplinary approach. Springer Berlin Heidelberg; 2018. 10.1007/978-3-319-67858-0.

3. Delacy MJ, Reid SM. Profile of associated impairments at age 5 years in Australia by cerebral palsy subtype and Gross Motor Function Classification System level for birth years 1996 to 2005. Developmental Med Child Neurol. 2016;58:50-56. doi:10.1111/ dmcn.2016.58.issue-S2.

4. Bleyenheuft Y, Gordon AM. Precision grip control, sensory impairments and their interactions in children with hemiplegic cerebral palsy: A systematic review. Res Dev Disabil. 2013;34:3014-28. doi:10.1016/j.ridd.2013.05.047.

5. Gordon AM, Bleyenheuft Y, Steenbergen B. Pathophysiology of impaired hand function in children with unilateral cerebral palsy. Developmental Med Child Neurol. 2013;55:32-37. doi:10.1111/ dmcn.2013.55.issue-s4.

6. Deluca SC, Echols K, Law CR, Ramey SL. Intensive pediatric constraint-induced therapy for children with cerebral palsy: randomized, controlled, crossover trial. J Child Neurol. 2006;21:931-38.

7. Taub E, Uswatte G, Mark VW, Morris DM. The learned nonuse phenomenon: implications for rehabilitation. Eura Medicophys. 2006;42:16.

8. Klingels K, Feys H, Molenaers G, Verbeke G, Van Daele S, Hoskens J, Desloovere K, De Cock P. Randomized trial of modified constraint-induced movement therapy with and without an intensive therapy program in children with unilateral cerebral palsy. Neurorehabil Neural Repair. 2013;27:799-807. doi:10.1177/1545968313496322.

9. Howard J, Soo B, Graham HK, Boyd RN, Reid S, Lanigan A, Wolfe R, Reddihough DS. Cerebral palsy in Victoria: motor types, topography and gross motor function. J Paediatr Child Health. 2005;41:479-83. doi:10.1111/jpc.2005.41.issue-9-10.

10. Novak I, Morgan C, Adde L, et al. Early, accurate diagnosis and early intervention in cerebral palsy: advances in diagnosis and treatment. JAMA Pediatr. 2017;171:897-907. doi:10.1001/ jamapediatrics.2017.1689.

11. Sakzewski L, Ziviani J, Boyd RN. Efficacy of Upper Limb Therapies for Unilateral Cerebral Palsy: A Meta-analysis. Pediatrics. 2014;133:e175-e204. doi:10.1542/peds.2013-0675.

12. Novak I, Mcintyre S, Morgan C, Campbell L, Dark L, Morton N, Stumbles E, Wilson S-A, Goldsmith S. A systematic review of interventions for children with cerebral palsy: state of the evidence. Dev Med Child Neurol. 2013;55:885-910. doi:10.1111/ dmcn.12246.

13. Chen Y, Pope S, Tyler D, Warren GL. Effectiveness of constraint-induced movement therapy on upper-extremity function in children with cerebral palsy: a systematic review and meta-analysis of randomized controlled trials. Clin Rehabil. 2014;28:939-53. doi:10.1177/0269215514544982.

14. Chiu H-C, Ada L. Constraint-induced movement therapy improves upper limb activity and participation in hemiplegic cerebral palsy: a systematic review. J Physiother. 2016;62:130-37. doi:10.1016/j.jphys.2016.05.013.

15. Dong VA-Q, Tung I-H-H, Siu HW-Y, Fong -KN-K. Studies comparing the efficacy of constraint-induced movement therapy and bimanual training in children with unilateral cerebral palsy: A systematic review. Dev Neurorehabil. 2013;16:133-43. doi:10.3109/17518423.2012.702136.

16. Durand E, Plante P, Pelletier -A-A, Rondeau J, Simard F, Voisin J. At-home and in-group delivery of constraint-induced movement therapy in children with hemiparesis: A systematic review. Ann Phys Rehabil Med. 2018;61:245-61. doi:10.1016/j. rehab.2017.10.004.
17. Rivas Guerrero OP. Parámetros de dosificación de la terapia de movimiento inducido por restricción en niños con parálisis cerebral hemipléjica. Revisión de la literatura. Rehabilitación. 2018;52:246-58. doi:10.1016/j.rh.2018.04.008.

18. Gordon AM, Hung Y-C, Brandao M, Ferre CL, Kuo H-C, Friel K, Petra E, Chinnan A, Charles JR. Bimanual training and constraint-induced movement therapy in children with hemiplegic cerebral palsy: a randomized trial. Neurorehabil Neural Repair. 2011;25:692-702. doi:10.1177/1545968311402508.

19. Wallen M, ZIVIANI J, NAYLOR O, EVANS R, NOVAK I, HERBERT RD. Modified constraint-induced therapy for children with hemiplegic cerebral palsy: a randomized trial. Dev Med Child Neurol. 2011;53:1091-99. doi:10.1111/dmcn.2011.53.issue-12.

20. SAKZEWSKI L, ZIVIANI J, ABBOTT DF, MACDONELL RAL, JACKSON GD, BOYD RN. Randomized trial of constraintinduced movement therapy and bimanual training on activity outcomes for children with congenital hemiplegia. Developmental Med Child Neurol. 2011;53:313-20. doi:10.1111/ dmcn.2011.53.issue-4.

21. Arpino C, Vescio MF, De Luca A, Curatolo P. Efficacy of intensive versus nonintensive physiotherapy in children with cerebral palsy: a meta-analysis. Int J Rehabil Res. 2010;33:165. doi:10.1097/ MRR.0b013e328332f617.

22. Tinderholt Myrhaug H, Østensjø S, Larun L, Odgaard-Jensen J, Jahnsen R. Intensive training of motor function and functional skills among young children with cerebral palsy: a systematic review and meta-analysis. BMC Pediatr. 2014;14:292. doi:10.1186/s12887-014-0292-5.

23. Kolobe THA, Christy JB, Gannotti ME, Heathcock JC, Damiano DL, Taub E, Majsak MJ, Gordon AM, Fuchs RK, O'Neil ME, et al. Research summit III proceedings on dosing in children with an injured brain or cerebral palsy: executive summary. Phys Ther. 2014;94:907-20. doi:10.2522/ptj.20130024.

24. Cope S, Mohn-Johnsen S. The effects of dosage time and frequency on motor outcomes in children with cerebral palsy: A systematic review. Dev Neurorehabil. 2017;20:376-87. doi:10.1080/17518423.2017.1282053.

25. Eliasson AC, Krumlinde-Sundholm L, Gordon AM, Feys H, Klingels K, Aarts PBM, Rameckers E, Autti-Rämö I, Hoare B. Guidelines for future research in constraint-induced movement therapy for children with unilateral cerebral palsy: an expert consensus. Dev Med Child Neurol. 2014;56:125-37. doi:10.1111/ dmcn.12273.

26. Page SJ, Schmid A, Harris JE. Optimizing terminology for stroke motor rehabilitation: recommendations from the american congress of rehabilitation medicine stroke movement interventions subcommittee. Arch Phys Med Rehabil. 2012;93:1395-99. doi:10.1016/j.apmr.2012.03.005.

27. Gannotti ME, Christy JB, Heathcock JC, Kolobe THA. A path model for evaluating dosing parameters for children with cerebral palsy. Phys Ther. 2014;94:411-21. doi:10.2522/ptj.20130022.

28. American College of Sports Medicine, D. Riebe, J. K. Ehrman,G. Liguori, and M. Magal. ACSM's guidelines for exercise testing and prescription, 10th edition. Lippincott Williams \& Wilkins, Philadelphia. 2017.

29. Avez-Couturier J, Joriot S, Peudenier S, Juzeau D. La douleur chez l'enfant en situation de handicap neurologique: mise au point de la Commission "déficience intellectuelle et handicap » de la Société française de neurologie pédiatrique. Archives De Pédiatrie. 2018;25:55-62. doi:10.1016/j.arcped.2017.11.012.

30. Feldman AB, Haley SM, Coryell J. Concurrent and construct validity of the pediatric evaluation of disability inventory. Phys Ther. 1990;70:602-10. doi:10.1093/ptj/70.10.602.

31. Uswatte G, Taub E, Griffin A, Rowe J, Vogtle L, Barman J. Pediatric arm function test. Am J Phys Med Rehabil. 2012;91:1060-69. doi:10.1097/PHM.0b013e318269ec76.

32. Lattre CD, Groupe R. Prise en charge non chirurgicale du membre supérieur de l'enfant hémiplégique : actualités sur l'évaluation, les traitements médicamenteux et les techniques rééducatives. 
Ann Phys Rehabil Med. 2012;55:e239-e240. doi:10.1016/j. rehab.2012.07.606.

33. Varni JW, Burwinkle TM, Berrin SJ, Sherman SA, Artavia K, Malcarne VL, Chambers HG. The PedsQL in pediatric cerebral palsy: reliability, validity, and sensitivity of the generic core scales and cerebral palsy module. Developmental Med Child Neurol. 2006;48:442-49. doi:10.1017/S001216220600096X.

34. Lemmens RJ, Timmermans AA, Janssen-Potten YJ, Smeets RJ, Seelen HA. Valid and reliable instruments for arm-hand assessment at ICF activity level in persons with hemiplegia: a systematic review. BMC Neurol. 2012;12:21. doi:10.1186/1471-2377-12-21.

35. Peters MDJ, Godfrey CM, Khalil H, McInerney P, Parker D, Soares CB. Guidance for conducting systematic scoping reviews. Int J Evid Based Healthc. 2015;13:141. doi:10.1097/ XEB.0000000000000050.

36. DeLuca SC, Case-Smith J, Stevenson R, Ramey SL. Constraintinduced movement therapy (CIMT) for young children with cerebral palsy: effects of therapeutic dosage. J Pediatr Rehabil Med. 2012;5:133-42. doi:10.3233/PRM-2012-0206.

37. Case-Smith J, DeLuca SC, Stevenson R, Ramey SL. Multicenter randomized controlled trial of pediatric constraint-induced movement therapy: 6-month follow-up. Am J Occup Ther. 2012;66:15-23. doi:10.5014/ajot.2012.002386.

38. Brandão MB, Ferre C, Kuo H-C, Rameckers EAA, Bleyenheuft Y, Hung Y-C, Friel K, Gordon AM. Comparison of structured skill and unstructured practice during intensive bimanual training in children with unilateral spastic cerebral palsy. Neurorehabil Neural Repair. 2014;28:452-61. doi:10.1177/1545968313516871.

39. Friel KM, Kuo H-C, Fuller J, Ferre CL, Brandão M, Carmel JB, Bleyenheuft Y, Gowatsky JL, Stanford AD, Rowny SB, et al. Skilled bimanual training drives motor cortex plasticity in children with unilateral cerebral palsy. Neurorehabil Neural Repair. 2016;30:834-44. doi:10.1177/1545968315625838.

40. Hung Y-C, Brandão MB, Gordon AM. Structured skill practice during intensive bimanual training leads to better trunk and arm control than unstructured practice in children with unilateral spastic cerebral palsy. Res Dev Disabil. 2017;60:65-76. doi:10.1016/j.ridd.2016.11.012.

41. Kirton A, Andersen J, Herrero M, Nettel-Aguirre A, Carsolio L, Damji O, Keess J, Mineyko A, Hodge J, Hill MD, et al. Brain stimulation and constraint for perinatal stroke hemiparesis. Neurology. 2016;86:1659-67. doi:10.1212/ WNL.0000000000002646.

42. Brandão MB, Mancini MC, Ferre CL, et al. Does dosage matter? A pilot study of Hand-Arm Bimanual Intensive Training (HABIT) dose and dosing schedule in children with unilateral cerebral palsy. Phys Occup Ther Pediatr. 2017;1-16. doi:10.1080/ 01942638.2017.1407014.

43. Sung I-Y, Ryu J-S, Pyun S-B, Yoo S-D, Song W-H, Park M-J. Efficacy of forced-use therapy in hemiplegic cerebral palsy. Arch Phys Med Rehabil. 2005;86:2195-98. doi:10.1016/j.apmr.2005.05.007.

44. Kumar C, Palshikar RM, Choubey V. Effect of manipulating object shape, size and weight combined with Hand- Arm Bimanual Intensive Training (HABIT) in improving upper extremity function in children with hemiplegic cerebral palsy-a randomized controlled trial. J Nov Physiother. 2017;07. doi:10.4172/2165-7025.

45. Chopra C, Kaur J. Supervised V/s unsupervised constraint induced movement therapy in improving upper extremity function in spastic hemiparetic cerebral palsy children. Indian J Physiother Occup Ther Int J. 2013;7:54. doi:10.5958/j.09735674.7.3.065

46. Sabour H, Rassafiani M, Hosseini SA, et al. Comparison of Combination of CIMT and BIM training with CIMT alone on fine motor skills of children with hemiplegic cerebral palsy. Iran Rehabili J. 2013;11:46-51.
47. Rostami HR, Malamiri RA. Effect of treatment environment on modified constraint-induced movement therapy results in children with spastic hemiplegic cerebral palsy: a randomized controlled trial. Disabil Rehabil. 2012;34:40-44. doi:10.3109/ 09638288.2011.585214.

48. El-Kafy EMA, Elshemy SA, Alghamdi MS. Effect of constraint-induced therapy on upper limb functions: A randomized control trial. Scand J Occup Ther. 2014;21:11-23.

49. Aarts PB, Jongerius PH, Geerdink YA, van Limbeek J, Geurts AC. Effectiveness of modified constraint-induced movement therapy in children with unilateral spastic cerebral palsy: a randomized controlled trial. Neurorehabil Neural Repair. 2010;24:509-18. doi:10.1177/1545968309359767.

50. Aarts PB, Jongerius PH, Geerdink YA, van Limbeek J, Geurts AC. Modified Constraint-Induced Movement Therapy combined with Bimanual Training (mCIMT-biT) in children with unilateral spastic cerebral palsy: how are improvements in arm-hand use established? Res Dev Disabil. 2011;32:271-79. doi:10.1016/j. ridd.2010.10.008.

51. Geerdink Y, Aarts P, Geurts AC. Motor learning curve and long-term effectiveness of modified constraint-induced movement therapy in children with unilateral cerebral palsy: A randomized controlled trial. Res Dev Disabil. 2013;34:923-31. doi:10.1016/j. ridd.2012.11.011.

52. Christmas PM, Sackley C, Feltham MG, Cummins C. A randomized controlled trial to compare two methods of constraint-induced movement therapy to improve functional ability in the affected upper limb in pre-school children with hemiplegic cerebral palsy: CATCH TRIAL. Clin Rehabil. 2018;32:909-18. doi:10.1177/0269215518763512.

53. Smorenburg ARP, Gordon AM, Kuo H-C, Ferre CL, Brandao M, Bleyenheuft Y, Carmel JB, Friel KM. Does corticospinal tract connectivity influence the response to intensive bimanual therapy in children with unilateral cerebral palsy? Neurorehabil Neural Repair. 2017;31:250-60. doi:10.1177/1545968316675427.

54. Bleyenheuft Y, Dricot L, Gilis N, Kuo H-C, Grandin C, Bleyenheuft C, Gordon AM, Friel KM. Capturing neuroplastic changes after bimanual intensive rehabilitation in children with unilateral spastic cerebral palsy: a combined DTI, TMS and fMRI pilot study. Res Dev Disabil. 2015;43-44:136-49. doi:10.1016/j. ridd.2015.06.014.

55. Ramey S, Coker-Bolt P, DeLuca S. Handbook of pediatricconstraint induced movement therapy. AOTA Press. 2013. doi:10.7139/2017.978-1-56900-472-2.

56. Aarts PB, Hartingsveldt M, Anderson PG, Tillaar I, Burg J, Geurts AC. The pirate group intervention protocol: description and a case report of a modified constraint-induced movement therapy combined with bimanual training for young children with unilateral spastic cerebral palsy: the pirate group intervention, a case report. Occupational Therapy International 19, 76-87 (2012). doi: 10.1002/oti.v19.2

57. Charles J, Gordon AM. Development of hand-arm bimanual intensive training (HABIT) for improving bimanual coordination in children with hemiplegic cerebral palsy. Dev Med Child Neurol. 2006;48:931-36. doi:10.1017/S0012162206002039.

58. Rostami HR, Arastoo AA, Nejad SJ, Mahany MK, Malamiri RA, Goharpey S. Effects of modified constraint-induced movement therapy in virtual environment on upper-limb function in children with spastic hemiparetic cerebral palsy: A randomised controlled trial. NeuroRehabilitation. 2012;31:357-65. doi:10.3233/ NRE-2012-00804.

59. Sakzewski L, Provan K, Ziviani J, Boyd RN. Comparison of dosage of intensive upper limb therapy for children with unilateral cerebral palsy: how big should the therapy pill be? Res Dev Disabil. 2015;37:9-16. doi:10.1016/j.ridd.2014.10.050. 